\title{
Model Problem Based Learning untuk Meningkatkan Hasil Belajar Tematik pada Muatan Pelajaran IPS
}

\author{
Luh Putu Shinta Destina Putri Utami ${ }^{1 *}$, I Gede Astawan², Made Krisnaningsih ${ }^{3}$ iD \\ 1,2,3 Prodi Pendidikan Guru Sekolah Dasar Universitas Pendidikan Ganesha \\ *Corresponding author: shintadestina@gmail.com
}

\begin{abstract}
Abstrak
Kegiatan belajar masih berpusat pada guru seperti berceramah. Hal ini mengakibatkan siswa menjadi pasif dalam proses pembelajaan dan berdampak pada hasil belajar siswa yang rendah. Penelitian ini bertujuan untuk menerapkan model pembelajaran PBL untuk meningkatkan pembelajaran IPS pada siswa sekolah dasar. Jenis penelitian ini adalah penelitian tindakan kelas yang terdiri dari empat tahapan yaitu perencanaan tindakan, pelaksanaan tindakan, observasi atau evaluasi dan refleksi. Subjek penelitian ini berjumlah 26 siswa. Teknik yang digunakan dalam mengumpulkan data yaitu obeservasi, wawancara, dan tes. Instrumen yang digunakan dalam mengumpulkan data yaitu lembaar kuesioner. Teknik yang digunakan untuk menganalisis data yaitu metode analisis statistik deskriptif dan metode analisis desktiptif kuantitatif. Hasil penelitian yaitu pada siklus I data hasil belajar muatan pelajaran IPS mencapai 63,07\% dengan kategori tinggi dan pada siklus II mencapai $80,76 \%$ berada pada kategori sangat tinggi. Dengan demikian, peningkatan hasil belajar muatan pelajaran IPS mencapai 17,69\%. Jadi penerapan model pembelajaran Problem Based Learning dapat meningkatkan hasil belajar muatan pelajaran IPS siswa kelas VI. Implikasi model pembelajaran Problem Based Learning memberikan kesempatan siswa menyampaikan ide/gagasan, dan meningkatkan keaktifan dalam proses pembelajaran.
\end{abstract}

Kata kunci: PBL, Hasil Belajar, IPS

\section{Abstract}

Learning activities are still teacher-centered, such as lecturing. This causes students to be passive in the learning process and has an impact on low student learning outcomes. This study aims to apply the PBL learning model to improve social studies learning for elementary school students. This type of research is classroom action research which consists of four stages, namely action planning, action implementation, observation or evaluation and reflection. The subjects of this study amounted to 26 students. The techniques used in collecting data are observation, interviews, and tests. The instrument used in collecting data is a questionnaire sheet. The techniques used to analyze the data are descriptive statistical analysis methods and quantitative descriptive analysis methods. The results of the research are that in the first cycle, the data on social studies learning outcomes reached $63.07 \%$ in the high category and in the second cycle it reached $80.76 \%$ in the very high category. Thus, the increase in learning outcomes for social studies subject matter reached $17.69 \%$. So the application of the Problem Based Learning learning model can improve the learning outcomes of social studies subject matter for grade VI students. The implications of the Problem Based Learning learning model provide opportunities for students to convey ideas, and increase activity in the learning process.

Keywords: PBL, Learning Outcomes, Social Studies

\section{INTRODUCTION}

Ilmu Pengetahuan sosial adalah bidang studi yang mempelajari, menelaah, menganalisis gejala dan masalah sosial di masyarakat dengan meninjau dari berbagai aspek kehidupan atau satu perpaduan (Aditya, 2017; Andhika, Suardika, \& Wiyasa, 2013; Mahardika, Dantes, \& Widiana, 2018). Mata pelajaran IPS di SD bertujuan untuk membentuk warga negara yang baik, yaitu warga negara yang memiliki kemampuan dan keterampilan yang berguna bagi diri dalam hidup sehari-hari dan warga negara yang bangga sebagai bangsa Indonesia dan cinta tanah air (Wati, Darsana, \& Suardika, 2014; Widnyana, Sujana, \& Putra, 2017). Dengan adanya pembelajaran IPS di SD diharapkan siswa tidak hanya mampu menguasai teori-teori kehidupan di dalam masyarakat tapi mampu menerapkan kehidupan nyata di masyarakat sebagai insan sosial. Warga negara yang mampu mengaplikasikan ilmunya dalam bentuk amalan nyata yang bermanfaat bagi kehidupan di masyarakat (Anggreni, Asri,

$\begin{array}{ll}\text { History: } & \\ \text { Received } & \text { : June 17, } 2021 \\ \text { Revised } & \text { : June 20, } 2021 \\ \text { Accepted } & \text { : October 10, } 2021 \\ \text { Published } & \text { : November 25, 2021 }\end{array}$


\& Ganing, 2017). Hal ini yang menyebabkan pembelajaran IPS sangat penting untuk diberikan kepada siswa. Keberhasilan pencapaian kompetensi suatu pembelajaran bergantung kepada beberapa aspek. Salah satu aspek yang sangat mempengaruhi kebehasilan pencapaian kompetensi, yaitu cara guru dalam melaksanakan pembelajaran (Fitriani \& Wuryandari, 2019; Sujana, Dharsana, \& Jayanta, 2018). Pembelajaran yang baik akan membantu siswa memahami materi pembelajaran sehingga tujuan pembelajaran dapat tercapai secara maksimal (Noge, Tegu, \& Kaka, 2020; Rahmatia et al, 2021). Guru harus mampu menciptakan pembelajaran inovatif yang dapat meningkatkan semangat siswa dalam belajar, sehingga berdampak pada hasil belajar yang meningkat.

Permasalahan yang terjadi saat ini yaitu proses pembelajaran di Indonesia adalah kegiatan belajar masih berpusat pada guru, yaitu guru lebih banyak bercerita atau berceramah (Noge et al., 2020; Pour \& Sukroyanti, 2018). Hal ini mengakibatkan siswa menjadi tidak aktif dalam proses pembelajaan. Selain itu, masih banyak guru yang tidak menggunakan media pembelajaran sehingga sehingga proses pembelajaran menjadi pasif dan kurang bermanfaat (Aditya, 2017; Hardiyanti, Husain, \& Nurabdiansyah, 2019; Nursyam, 2019). Hal itu juga terjadi pada pembelajaran tematik terutamanya di muatan pelajaran IPS, Berdasarkan yang dilakukan di SD Negeri 2 Gitgit, ditemukan permasalahan yaitu belum optimalnya hasil belajar siswa terutama pada muatan pelajaran IPS. KKM muatan pelajaran IPS di SD Negeri 2 Gitgit yaitu 60. Berdasarkan hasil ulangan harian terdapat 9 dari 13 siswa yang tidak mencapai KKM yang telah ditetapkan. Selain itu, pembelajaran khususnya pada muatan pelajaran IPS masih berorientasi pada guru sebagai pusat pembelajaran. Model pembelajaran yang berpusat pada guru membuat siswa hanya mendengarkan dan menerima penyampaian guru sehingga siswa menjadi bosan dalam belajar (Sujana et al., 2018; Triana, Garminah, \& Suartama, 2016). Sistem belajar yang demikian menyebabkan siswa kurang berpartisipasi aktif dalam mengikuti pembelajaran, sehingga menunjukkan hasil belajar IPS belum optimal.

Solusi yang ditawarkan untuk mengatasi permasalahan tersebut yaitu menggunakan model pembelajaran yang bervariasi. Model pembelajaran inovatif dapat membantu siswa dalam memahami materi pembelajaran (Sutama, Dibia, \& Margunayasa, 2017; Triana et al., 2016). Guru perlu menerapkan pembelajaran yang menuntut siswa untuk berani mengajukan pertanyaan, menyatakan pendapat, menanggapi pendapat orang lain, dan berinisiatif untuk mengembangkan ide/gagasan serta menciptakan hal-hal baru (Putri, Ardana, \& Agustika, 2019; Taqiya, Nuroso, \& Reffiane, 2019). Salah satunya adalah dengan menerapkan metode problem based learning. Problem Based Learning menyajikan masalah tentang dunia nyata yang diselesaikan dengan peserta didik melalui bekerjasama dalam kelompok, memecahkan masalah dengan pengetahuannya dan dengan mencari informasi yang relevan (Awaludin, Wibawa, \& Winarsih, 2020; Kamisa, 2016; Nur, Pujiastuti, \& Rahman, 2016). Problem Based Learning merupakan kegiatan pembelajaran yang diarahkan oleh suatu permasalahan seharihari. Pembelajaran ini dilakukan dengan cara menyajikan suatu permasalahan, pertanyaan pertanyaan, memfasilitasi penyelidikan dan membuka dialog (Kimianti \& Prasetyo, 2019; Sofyan, 2016). Pembelajaran ini mendorong peserta didik untuk mengetahui cara dalam belajar dan bekerjasama terhadap kelompok untuk memecahkan suatu masalah (Daniel, 2016; Dwi, Arif, \& Sentot, 2013). PBL mempersiapkan peserta didik untuk berfikir kritis dan analistis dan untuk mencari serta menggunakan sumber pembelajaran yang sesuai. Peran guru pada model Problem Based Learning yaitu sebagai sumber pemberi masalah, memfasilitasi investigasi dan dialog, serta menjadi motivator dalam pembelajaran (Rozhana \& Harnanik, 2019; Winursiti, 2017). Selain itu, guru juga berperan dalam mengembangkan aspek kognitif siswa bukan sekedar memberikan informasi. Dengan menjadi fasilitator guru akan dapat menciptakan pembelajaran yang aktif, yaitu merupakan proses pembelajaran di mana seorang guru harus dapat menciptakan suasana yang sedemikian rupa sehingga siswa aktif bertanya, mempertanyakan dan juga mengemukakan gagasannya (Hadi \& Rahmantika, 2016). 
Temuan penelitian sebelumnya menyatakan bahwa model Problem Based Learning dapat meningkatkan motivasi serta semangat siswa dalam belajar (Gunantara, Suarjana, \& Riastini, 2014; Ningsih, Arif Hidayat, \& Kusairi, 2018). Penelitian lainnya juga menyatakan bahwa model Problem Based Learning dapat memudahkan siswa dalam belajar sehingga dapat meningkatkan hasil belajar siswa (Dwi et al., 2013; Rozhana \& Harnanik, 2019; Winursiti, 2017). Belum adanya kajian secara mendalam mengenai model $P B L$ untuk meningkatkan pembelajaran IPS pada siswa sekolah dasar. Kelebihan model $P B L$ ini yaitu meningkatkan kemampuan berpikir kritis, memotivasi siswa untuk belajar, serta memberikan kesempatan untuk mengaplikasikan pengetahuan siswa kedunia nyata (Gunantara et al., 2014; Hadi \& Rahmantika, 2016). Tujuan penelitian ini yaitu untuk menerapkan model pembelajaran $P B L$ untuk meningkatkan pembelajaran IPS pada siswa sekolah dasar. Diharapkan model pembelajaran ini dapat memotivasi siswa dalam belajar IPS sehingga berdampak pada hasil belajar IPS yang meningkat.

\section{MATERIALS AND METHODS}

Penelitian ini termasuk jenis penelitian tindakan kelas(PTK) atau Classroom Action Research (CAR). Pelaksanaan penelitian ini mengadaptasi model pelaksanaan penelitian kelas menurut Kemmis \& Taggart. Penelitian ini berlangsung selama 2 siklus, dimana setiap siklusnya terdiri dari tiga kali pelaksanaan tindakan. Penelitian ini terdiri dari empat tahap yaitu perencanaan tindakan, pelaksanaan tindakan, observasi atau evaluasi dan refleksi. Subjek dalam penelitian ini adalah siswa kelas VI semester II tahun pelajaran 2020/2021 dengan jumlah siswa sebanyak 13 orang yang terdiri dari 7 orang siswa laki-laki dan 6 orang siswa perempuan. Lokasi penelitian dilakukan di SD Negeri 2 Gitgit. Teknik yang digunakan dalam mengumpulkan data yaitu observasi, wawancara, dan tes. Instrumen yang digunakan dalam mengumpulkan data yaitu tes hasil belajar IPS. Adapun kisi-kisi instrumen tersebut disajikan pada Tabel 1.

Tabel 1. Kisi-kisi Instrumen Hasil Belajar IPS

\begin{tabular}{lll}
\hline \multicolumn{1}{c}{ Kompetensi Dasar } & $\begin{array}{c}\text { Materi } \\
\text { Pokok }\end{array}$ & \multicolumn{1}{c}{ Indikator Soal } \\
\hline 3.3 Menganalisis posisi & ASEAN & $\begin{array}{l}\text { 3.3.1 Disajikan soal, siswa dapat menganalisis } \\
\text { kepanjangan dari ASEAN }\end{array}$ \\
dan peran Indonesia dalam & & $\begin{array}{l}\text { 3.3.2 Disajikan gambar bendera, siswa dapat } \\
\text { kerja sama di bidang }\end{array}$ \\
ekonomi, politik, sosial, & menentukan keanggotaan dari ASEAN \\
budaya, teknologi, dan & 3.3.3 Disajikan soal, siswa dapat menentukan \\
pendidikan dalam lingkup & peran Indonesia di ASEAN dalam bidang \\
ASEAN. & ekonomi \\
& 3.3.4 Disajikan soal, siswa dapat menentukan \\
& produk yang diekspor oleh Indonesia \\
\hline
\end{tabular}

Teknik yang digunakan untuk menganalisis data yaitu metode analisis statistik deskriptif dan metode analisis desktiptif kuantitatif. Indikator keberhasilan dari penelitian ini jika ditinjau dari hasil belajar muatan pelajaran IPS setelah diterapkannya model Problem Based Learning dalam pembelajaran, hasil belajar muatan pelajaran IPS cenderung meningkat ke kategori tinggi atau sangat tinggi dengan perolehan nilai 70 dengan kategori tinggi. Apabila indikator keberhasilan penelitian sudah tercapai, maka penelitian dapat dihentikan dan dibuat suatu simpulan dari hasil penelitian yang telah dilakukan. Acuan yang digunakan untuk menentukan keberhasilan siswa yaitu konversi PAP Skala 5. Konversi PAP Skala 5 disajikan pada Tabel 2. 
Tabel 2. Pedoman Konversi PAP Skala Lima Tentang Tingkatan Hasil Belajar Muatan Pelajaran IPS

\begin{tabular}{cc}
\hline Persentase & Kriteria hasil belajar IPS \\
\hline $75-100$ & Sangat tinggi \\
$58-74$ & Tinggi \\
$42-57$ & Cukup tinggi \\
$25-41$ & Kurang tinggi \\
$0-25$ & Sangat kurang tinggi \\
\hline & (Nurkanca \& Sunartana, 1992)
\end{tabular}

\section{RESULTS AND DISCUSSION}

\section{Results}

Pada penelitian ini yang diteliti adalah hasil belajar IPS dengan menerapkan model problem based learning. Penelitian ini dirancang melalui beberapa siklus hingga menemukan tindakan yang terbaik. Pada siklus I terdiri dari perencanaan, pelaksanaan, observasi atau evaluasi dan refleksi siklus I. Apabila belum berhasil akan dilanjutkan ke siklus II yang terdiri dari perencanaan, pelaksanaan, observasi atau evaluasi dan refleksi siklus II. Apabila berhasil maka penelitian akan dihentikan karena telah mencapai target yang ditentukan. Pelaksanaan Tindakan pada siklus I dilaksanakan mulai tanggal 20 - 25 Februari dengan 3 kali pertemuan. Kegiatan pembelajaran dilaksanakan pada pertemuan I dan pertemuan II, serta pada pertemuan III dilakukan evaluasi hasil belajar IPS dengan menggunakan soal pilihan ganda. Secara umum pelaksanaan Tindakan dilaksanakan dalam lima fase kegiatan pembelajaran sesuai dengan fase yang ada pada model Problem Based Learning. Kelima fase tersebut yaitu : fase ke-1 : memberikan orientasi masalah pada siswa. Fase ke-2: mengorganisasi siswa untuk meneliti atau belajar. Fase ke-3: mendampingi pengalaman/ penyelidikan individual/ kelompok. Fase ke-4: mengembangkan dan menyajikan hasil. Fase ke- 5: menganalisis dan mengevaluasi proses pemecahan masalah. Data hasil belajar IPS dalam pembelajaran dengan menerapkan model Problem Based Learning, diperoleh dari tes hasil belajar IPS. Perolehan skor dan pengkategorian hasil belajar IPS yang diperoleh dari tes pada akhir siklus I yaitu 63,07. Berdasarkan hasil analisis data siklus I, maka tingkat hasil belajar IPS secara klasikal dalam muatan pembelajaran mencapai 63,07 dengan skor perolehan 820. Presentase hasil belajar IPS siswa kelas VI adalah 63,07\%, dan apabila dikonversikan de dalam PAP skala lima untuk kriteria hasil belajar IPS secara klasikal maka hasil belajar IPS untuk siklus I tergolong tinggi.

Analisis data hasil belajar IPS diperoleh hasil bahwa secara klasikal hasil belajar IPS sebesar 63,07 dengan presentase 63,07\% berada pada kategori tinggi. Dari hasil pengamatan dan temuan selama pemberian tindakan pada siklus I terdapat beberapa masalah yang menyebabkan hasil belajar IPS belum mencapai target yang diharapkan. Masalah yang ditemukan yaitu siswa belum terbiasa dengan model Problem Based Learning sehingga dalam penerapannya belum efektif. Hal tersebut disebabkan karena model problem based learning berbeda dengan model yang biasa digunakan, dalam diskusi kelompok maupun pengamatan secara individu, masih banyak siswa yang hanya berdiam diri dan melamun. Ketika ditanya ada atau tidak permasalahan siswa hanya menjawab tidak. Masih banyak siswa yang kurang aktif dalam tanya jawab, hal ini disebabkan siswa terlihat canggung dan malu. Saat presentasi, penyampaian siswa atas hasil pengamatan belum lugas dan terkesan belum berani menyampaikan pendapat atau gagasan. Sarana dan prasarana pendukung pembelajaran terbatas serta ruang gerak pembelajaran tatap muka dikelas pun terbatas akibat dari pandemi.

Selanjutnya dilakukan perancangan perbaikan tindakan untuk selanjutnya diterapkan pada siklus II. Adapun langkah-langkah rencana siklus II adalah sebelum melaksanakan Tindakan pada siklus II, siswa diberikan penjelasan dan pemahaman tentang model problem based learning beserta kegiatan dan langkah-langkah pembelajaran yang akan diterapkan agar 
siswa memiliki kesiapan dan pemahaman dalam mengikuti pembelajaran. Dalam diskusi kelompok maupun pengamatn individu guru mengawasi dan membimbing siswa agar seluruh siswa ikut berpartisipasi dalam kegiatan kelompok maupun pengamatan individu. Memberikan motivasi dan penguatan kepada siswa agar lebih aktif untuk bertanya maupun menjawab pertanyaan. Guru memberikan motivasi agar siswa percaya diri dalam menyampaikan hasil diskusi dan tidak takut jika jawaban atau hasil yang disampaikan masih kurang tepat. Memanfaatkan sebaik mungkin sarana dan prasaran yang tersedia serta tetap menerapkan protocol Kesehatan dalam pelaksanaan pembelajaran. Data hasil belajar IPS dengan menerapkan model problem based learning, diperoleh dari tes hasil belajar IPS. Berdasarkan hasil analisis data siklus II, maka tingkat hasil belajar IPS secara klasikal dalam muatan pembelajaran mencapai 80,76 dengan skor perolehan 1050. Presentase hasil belajar IPS siswa kela VI adalah $80,76 \%$ dan apabila dikonversikan ke dalam PAP skala lima untuk kriteria hasil belajar IPS secara klasikal, maka hasil belajar IPS untuk siklus II tergolong sangat tinggi.

Setelah dilaksanakan tindakan pada siklus II, hasil yang dicapai siswa mengalami peningkatan. Kendala yang dihadapi pada siklus I dapat diatasi di siklus II, terbukti dengan adanya peningkatan hasil belajar IPS pada siklus II yaitu menjadi $80,76 \%$ berada pada kategori sangat tinggi. Hal ini menunjukkan bahwa pembelajaran dengan menerapkan model problem based learning berlangsung dengan baik. Setelah dilaksanakan siklus II, kembali diadakan refleksi. Pada refleksi II ternyata kelemahan yang terjadi pada sikllus I dapat diatasi di siklus II. Adapun yang menjadi refleksi di siklus II adalah sebagai berikut: Siswa mulai terbiasa dengan model Problem Based Learning dan seluruh siswa terlibat secara penuh dalam pembelajaran. Beberapa siswa yang kurang aktif pada siklus I, dengan bimbingan pada siklus II sudah mulai aktif dalam bertanya maupun menjawab pertanyaan. Dalam kegiatan memecahkan masalah, siswa terlihat antusias meskipun harus bekerja secara individu karena terhalang pandemi. Pada saat menyajikan hasil pemecahan masalah, siswa mengemukakannya dengan lugas dan percaya diri. Pada refleksi siklus II dilakukan refleksi akhir dengan tujuan memperoleh gambaran umum mengenai hasil belajar IPS dalam penelitian ini. Presentase ratarata hasil belajar IPS secara klasikal mengalami peningkatan dari 63,07\% menjadi 80,76\% yaitu sebesar 17,69\%.

Berdasarkan hasil analisis data, kriteria keberhasilan penelitian telah tercapai. Hal ini dibuktikan dengan hasil belajar IPS yang diperoleh pada siklus II secara individu sudah pada kategori tinggi dan sanagt tinggi dan secara klasikal diperoleh presentase $80,76 \%$ yang tergolong sangat tinggi. Dari hasil perbandingan antara hasil yang telah dicapai dengan target yang ditetapkan, dapat dijadikan pedoman untuk mengambil suatu keputusan bahwa Penelitian Tindakan Kelas yang dilaksanakan dapat dihentikan pada siklus II. Berdasarkan hasil analisis siklus I presentase hasil belajar IPS mencapai 63,0\% dengan kategori tinggi namun hasil belajar secara individu terdapat siswa yang memiliki hasil belajar dengan kategori kurang tinggi dan beberapa lainnya cukup tinggi. Sedangkan pada siklus II presentase hasil belajar IPS mencapai 80,76\% dengan kategori sangat tinggi dan secara individu presentase hasil belajar siswa ada pada kategori tinggi dan sangat tinggi. Hal ini menunjukkan adanya peningkatan presentase hasil belajar sebesar 17,69\% dari siklus I ke siklus II dan terjadi peningkatan hasil belajar siswa secara individu dan rata - rata klasikal secara keseluruhan. Maka, model $P B L$ untuk meningkatkan pembelajaran IPS pada siswa sekolah dasar.

\section{Discussion}

Hasil penelitian menunjukkan bahwa adanya peningkatan presentase hasil belajar sebesar dari siklus I ke siklus II dan terjadi peningkatan hasil belajar siswa secara individu dan rata - rata klasikal secara keseluruhan. Hal ini tidak terlepas dari beberapa faktor. Pertama, model PBL dapat meningkatkan hasil belajar siswa disebabkan karena siswa tertarik dalam belajar. Saat penerapan model ini siswa sangat antusias mengikuti pembelajaran karena 
pembelajaran berpusat pada siswa. PBL merupakan pembelajaran inovatif yang akan memberikan kondisi belajar aktif pada siswa (Choi, Lindquist, \& Song, 2014; Jahro \& Ridho, 2015). Pembelajaran ini memberikan permasalahan pada siswa sehingga siswa memiliki antusias untuk memecahkan permasalahan yang diberikan. Selain itu model ini juga dapat meningkatkan berpikir kritis pada siswa dan membantu siswa mengembangkan keterampilan pemecahan masalah (Husnah, 2017; Lukitasari, Purnamasari, Utami, \& Sukri, 2019; Nuswowati, Susilaningsih, Ramlawati, \& Kadarwati, 2017). Pembelajaran ini mendidik siswa untuk berpikir kritis dan mampu mendukung peningkatan kreaivitas siswa dalam berpikir kritis dan kreatif (Nadhifah \& Afriansyah, 2016; Yazar Soyad1, 2015). Pembelajara ini melibatkan seluruh siswa secara penuh sehingga dapat meningkatkan keaktifan siswa. Selain itu model ini akan meningkatkan semangat belajar siswa (Herzon, Budijanto, \& Utomo, 2018).

Kedua, model PBL dapat meningkatkan hasil belajar siswa disebabkan karena siswa lebih mudah memahami materi pembelajaran yang disampaikan oleh guru. Model pembelajaran ini menekankan pembelajaran yang aktif sehingga akan memudahkan siswa dalam mempelajari materi (Abdurrozak \& Jayadinata, 2016; Putra \& Amalia, 2020). Model pembelajaran ini akan melatih kemampuan untuk menyelesaikan masalah yang berasal dari kehidupan aktual yang dapat merangsang kemampuan berfikir tingkat tinggi pada siswa (Asyari, Henie, Muhdhar, \& Ibrahim, 2016; Wahyuni, Margunayasa, \& Wibawa, 2017). Kemampuan berpikir tingkat tinggi ini juga akan memudahkan siswa dalam memahami materi pembelajaran. Model ini menggunakan sistem pembelajaran yang secara stimulan merupakan strategi pemecahan masalah dan menempatkan peserta didik memiliki peran aktif (Wulandari \& Suparno, 2020). Kelebihan dari model pembelajarna ini yaitu siswa dituntut untuk meyelesaikan masalah dalam situasi nyata, siswa juga harus membangun pengetahuannya sendiri, dan pembelajaran berfokus pada masalah sehingga siswa lebih mudah memahami materi yang diajarkan oleh guru (Andriyani \& Suniasih, 2021; Fauzia, 2018; Kristinawati, Susilo, \& Gofur, 2018).

Ketiga, model PBL dapat meningkatkan hasil belajar siswa disebabkan karena model ini menciptakan suasana belajar yang menyenangkan. Keaktifan siswa ini sangat penting untuk membentuk generasi yang kreatif, yang mampu menghasilkan sesuatu untuk kepentingan dirinya dan juga orang lain, dan juga guru harus dapat membuat proses pembelajaran yang menyenangkan, yaitu berkaitan erat dengan suasana belajar yang menyenangkan (Nadhifah \& Afriansyah, 2016; Yazar Soyad1, 2015). Model pembelajaran ini dapat memusatkan perhatiannya secara penuh pada belajarnya. Hal ini membutuhkan kreativitas guru untuk dapat menghidupkan suasana belajar mengajar sehingga menjadi tidak membosankan bagi para siswanya (Herzon et al., 2018; Putri, Munzir, \& Abidin, 2019). Model problem based learning dapat dijadikan sebagai salah satu solusi guru dalam mengatasi permasalahan yang terjadi pada siswa dan dapat menciptakan suasana belajar yang menyenangkan. Pada model ini siswa diberikan tanggung jawab untuk menyelesaikan permasalahan selain itu siswa juga dituntut untuk dapat mempresetasikan atau mendemonstrasikan kinerja yang telah dipelajari (Rahayu \& Fahmi, 2018; Syairani \& Tarigan, 2015). Hal ini yang menyebabkan suasana belajar menjadi menyenangkan.

Temuan penelitian sebelumnya juga menyatakan bahwa model problem based learning dapat meningkatkan hasil belajar siswa (Anugraheni, 2018; Haryati, 2017; Ningsih et al., 2018). Temuan penelitian lainnya juga menyatakan bahwa model problem based learning dapat meningkatkan pemahaman siswa dan menambah motivasi siswa dalam belajar (Jahro \& Ridho, 2015; Lukitasari et al., 2019). Kelebihan model $P B L$ ini yaitu meningkatkan kemampuan berpikir kritis, memotivasi siswa untuk belajar, serta memberikan kesempatan untuk mengaplikasikan pengetahuan siswa kedunia nyata (Gunantara et al., 2014; Hadi \& Rahmantika, 2016). Dapat disimpulkan bahwa model problem based learning memudahkan siswa dalam belajar. Keterbatasan penelitian ini yaitu penerapan model Problem based 
learning hanya pada mata pelajaran muatan IPS. Implikasi penelitian ini yaitu model problem based learning dapat meningkatkan hasil belajar siswa secara signifikan dan meningkatkan semangat siswa dalam belajar.

\section{CONCLUSION}

Penerapan model problem based learning dapat meningkatkan hasil belajar IPS baik secara individu dan rata-rata klasikal siswa. Guru dapat menggunakan model problem based learning sehingga dapat meningkatkan semangat siswa dalam belajar dan akan berdampak pada hasil belajar siswa yang meningkat.

\section{REFERENCES}

Abdurrozak, R., \& Jayadinata, A. K. (2016). Pengaruh Model Problem Based Learning Terhadap Kemampuan Berpikir Kreatif Siswa. Pengaruh Model Problem Based Learning Terhadap Kemampuan Berpikir Kreatif Siswa, 1(1), 871-880. https://doi.org/10.23819/pi.v1i1.3580.

Aditya, A. (2017). Penggunaan Media Pembelajaran Audio Visual Untuk Meningkatkan Hasil Belajar IPS Pada Siswa Kelas IV SD. Mimbar Sekolah Dasar, 4(1). https://doi.org/10.23819/mimbar-sd.v4i1.5227.

Andhika, I. M. E., Suardika, W. R., \& Wiyasa, I. K. N. (2013). Pengaruh Model Pembelajaran Kooperatif Tipe Inside Outside Circle Berbasis Media Audio Visual Animation Terhadap Hasil Belajar IPS. Mimbar PGSD Undiksha, 1(1). http://dx.doi.org/10.23887/jjpgsd.v1i1.950.

Andriyani, N. L., \& Suniasih, N. W. (2021). Development Of Learning Videos Based On Problem-Solving Characteristics Of Animals And Their Habitats Contain in Science Subjects On 6th-Grade. Journal of Education, 5(1), 37-47. http://dx.doi.org/10.23887/jet.v5i1.32314.

Anggreni, P. F., Asri, I. A. S., \& Ganing, N. N. (2017). Pengaruh Model Pembelajaran Kooperatif Tipe Think- Pair-Share ( Tps ) Berbantuan Media Kartu Bergambar Terhadap Penguasaan Kompetensi Pengetahuan Ips Siswa Kelas V Gugus Letkol Wisnu. Mimbar PGSD, 5(2), 1-10. http://dx.doi.org/10.23887/jjpgsd.v5i2.10645.

Anugraheni. (2018). Meta Analisis Model problem based learning dalam Meningkatkan Keterampilan Berpikir Kritis di Sekolah Dasar. A Journal of Language, Literature, Culture, and Education, 14(1). http://dx.doi.org/10.19166/pji.v14i1.789.

Asyari, M., Henie, M., Muhdhar, I. Al, \& Ibrahim, H. S. (2016). Improving critical thinking skills through the integration of problem based learning and group investigation. International Journal for Lesson and Learning Studies, 5(1), 36-44. http://dx.doi.org/10.1108/IJLLS-10-2014-0042.

Awaludin, Wibawa, \& Winarsih. (2020). Integral Calculus Learning Using Problem Based Learning Model Assisted by Hypermedia-Based E-Book. Jurnal Pendidikan Indonesia, 9(2). http://dx.doi.org/10.23887/jpi-undiksha.v9i2.23106.

Choi, E., Lindquist, R., \& Song, Y. (2014). Effects of problem-based learning vs. traditional lecture on Korean nursing students' critical thinking, problem-solving, and self-directed learning. $\quad$ Nurse Education Today, 34(1), 52-56. https://doi.org/10.1016/j.nedt.2013.02.012.

Daniel, E. (2016). The Usefulness of Qualitative and Quantitative Approaches and Methods in Researching Problem-Solving Ability in Science Education Curriculum. Journal of Education and Practice, 7(15), 91-100. https://doi.org/2222-288X.

Dwi, Arif, \& Sentot. (2013). Pengaruh Strategi Problem Based Learning Berbasis ICT 
Terhadap Pemecahan Konsep dan Kemampuan Pemecahan Masalah Fisika. Jurnal Pendidikan Fisika Indonesia, 9(1). https://doi.org/10.15294/jpfi.v9i1.2575.

Fauzia, H. A. (2018). Penerapan Model problem based learning Untuk Meningkatkan Hasil Belajar Matematika Sd. Primary: Jurnal Pendidikan Guru Sekolah Dasar, 7(1), 40. https://doi.org/10.33578/jpfkip.v7i1.5338.

Fitriani, K., \& Wuryandari, W. (2019). Media Kajian Kewarganegaraan Pengaruh model kooperatif tipe Think Pair Share terhadap kerja sama siswa. Jurnal Civics, 16(1), 8088. https://doi.org/10.21831/jc.v16i1.21520.

Gunantara, Suarjana, \& Riastini. (2014). Penerapan Model problem based learning Untuk Meningkatkan Kemampuan Pemecahan Masalah Matematika Siswa Kelas V. Jurnal Mimbar PGSD Universitas Pendidikan Ganesha, 2(1). http://dx.doi.org/10.23887/jjpgsd.v2i1.2058.

Hadi, \& Rahmantika. (2016). Penerapan Pembelajaran Problem Based Learning (PBL) untuk Meningkatkan Hasil Belajar Matematika Siswa Kelas IV Sekolah Dasar. Jurnal Profesi Pendidikan Dasar, 3(2), 84-91. https://doi.org/10.23917/ppd.v3i2.2925.

Hardiyanti, Y., Husain, M. S., \& Nurabdiansyah. (2019). Perancangan Media Pengenalan Warna Untuk Anak Usia Dini. Jurnal Imajinasi Seni Dan Pendidikan, 2(2). https://doi.org/10.26858/i.v2i2.9553.

Haryati, Y. (2017). Model Problem Based Learning Membangun Kemampuan Berpikir Kritis Siswa Sekolah Dasar. Jurnal Cakrawala Pendas, 3(2), 57-63. http://dx.doi.org/10.31949/jcp.v3i2.596.

Herzon, H. H., Budijanto, \& Utomo, D. H. (2018). Pengaruh Problem-Based Learning (PBL) terhadap Keterampilan Berpikir Kritis. Jurnal Pendidikan: Teori, Penelitian, Dan Pengembangan, 3(1), 42-46.

Husnah, M. (2017). Hubungan Tingkat Berpikir Kritis Terhadap Hasil Belajar Fisika Siswa Dengan Menerapkan Model Pembelajaran Problem Based Learning. Journal of Physics and Science Learning (PASCAL), 01(2), 10-17. https://doi.org/10.1088/17426596/1157/3/032009.

Jahro, S., \& Ridho, D. (2015). Penerapan Model Problem Based Learning Menggunakan Media Exe Learning untuk Meningkatkan Hasil Belajar dan Kerjasama Siswa Pada Materi Hidrokarbon. Jurnal Pendidikan Kimia, 7(3), 80-86. https://doi.org/10.24114/jpkim.v7i3.4261.

Kamisa, A. (2016). Penerapan Model Problem Based Learning Dalam Pembelajaran Sejarah Untuk Meningkatkan Motivasi Dan Prestasi Belajar Siswa Kelas XI IPS 1 Sman 1 Butar Sulawesi Tengah. Jurnal Pendidikan Dan Sejarah, 12(1). https://doi.org/10.21831/istoria.v12i1.9542.

Kimianti, \& Prasetyo. (2019). Pengembangn E-Modul Ipa Berbasis Problem Based Learning Untuk Meningkatkan Literasi Sains Siswa. Kwangsan Jurnal Teknologi Pendidikan, 7(2), 91-103. http://doi.org/10.31800/jtp.kw.v7n2.p91--103.

Kristinawati, E., Susilo, H., \& Gofur, A. (2018). ICT Based-Problem Based Learning on Students' Cognitive Learning Outcomes. Jurnal Pendidikan Sains, 6(2), 38-42. http://dx.doi.org/10.17977/jps.v6i2.11683.

Lukitasari, Purnamasari, Utami, \& Sukri. (2019). Blended-Problem-Based Learning: How its impact on students' critical thingking skills? Jurnal Pendidikan Biologi Indonesia, 5(3), 425-434. https://doi.org/10.22219/jpbi.v5i3.10048.

Mahardika, I. P. M., Dantes, \& Widiana. (2018). Pengaruh Model Pembelajaran Numbered Heads Together Terhadap Hasil Belajar IPS Pada Siswa Kelas V SD Gugus V Kintamani Tahun Pelajaran. MIMBAR PGSD Undiksha, 6(1), 1-8. http://dx.doi.org/10.23887/jjpgsd.v6i1.13069.

Nadhifah, G., \& Afriansyah, E. A. (2016). Peningkatan Kemampuan Pemecahan Masalah 
Matematis Siswa dengan Menerapkan Model problem based learning dan Inquiry. Jurnal Mosharafa, 5(1).

Ningsih, P. R., Arif Hidayat, \& Kusairi, S. (2018). Penerapan Problem Based Learning Untuk Meningkatkan Kemampuan Berpikir Kritis Dan Hasil Belajar Siswa Kelas III. Jurnal Pendidikan, 3(12), 1587-1593. http://dx.doi.org/10.17977/jptpp.v3i12.11799.

Noge, M. D., Tegu, Y. I., \& Kaka, P. W. (2020). Model Pembelajaran Kooperatif Tipe InsideOutside Circle dalam Pembelajaran Bilingual Terhadap Hasil Belajar Siswa. Jurnal Kependidikan, 6(3). https://doi.org/10.33394/jk.v6i3.2640.

Nur, S., Pujiastuti, \& Rahman. (2016). Efektivitas Model Problem Based Learning (PBL) terhadap Hasil Belajar Mahasiswa Prodi Pendidikan Biologi Universitas Sulawesi Barat. Jurnal Saintifik, 2(2). https://doi.org/10.31605/saintifik.v2i2.105.

Nurkanca \& Sunartana. (1992). Evaluasi Hasil Belajar. Surabaya: Usaha Nasional.

Nursyam, A. (2019). Peningkatan Minat Belajar Siswa Melalui Media Pembelajaran Berbasis Teknologi Informasi. Jurnal Penelitian Hukum Dan Pendidikan, 18(1), 811-819. http://dx.doi.org/10.30863/ekspose.v18i1.371.

Nuswowati, M., Susilaningsih, E., Ramlawati, \& Kadarwati, S. (2017). Implementation of problem-based learning with green chemistry vision to improve creative thinking skill and students' creative actions. Jurnal Pendidikan IPA Indonesia, 6(2), 221-228. https://doi.org/10.15294/jpii.v6i2.9467.

Pour, \& Sukroyanti. (2018). Pengaruh Model Pembelajaran Talking Stick terhadap Keaktifan Belajar Siswa. Jurnal Penelitian Dan Pengkajian Ilmu Pendidikan: E-Saintika, 2(1), 36. https://dx.doi.org/10.36312/e-saintika.v2i1.111.

Putra, E. D., \& Amalia, R. (2020). Upaya Meningkatkan Kemampuan Berpikir Kritis Mahasiswa Melalui Pembelajaran Discovery Learning Berbasis Assessment Learning. Journal of Education and Learning Mathematics Research (JELMaR), 1(1), 57-64. https://doi.org/10.37303/jelmar.v1i1.17.

Putri, Ardana, \& Agustika. (2019). Pengaruh Model Discovery Learning Berbantuan Lingkungan Terhadap Kompetensi Pengetahuan IPA Siswa Kelas V. Mimbar PGSD, 7(2), 57-64. http://dx.doi.org/10.23887/jjpgsd.v7i2.17471.

Putri, C. A., Munzir, S., \& Abidin, Z. (2019). Kemampuan Berpikir Kreatif Matematis Siswa melalui Model Pembelajaran Brain-Based Learning. Jurnal Didaktik Matematika Universitas Syiah Kuala, 6(1), 12-27. https://doi.org/10.24815/jdm.v6i1.9608.

Rahayu, E., \& Fahmi, S. (2018). Efektivitas penggunaan model problem based Learning (PBL) dan inkuiri terhadap hasil belajar matematika siswa SMP N 1 Kasihan Kabupaten Bantul semester genap tahun ajaran 2017/2018. JURING (Journal for Research in Mathematics Learning), 1(2), 147. https://doi.org/10.24014/juring.v1i2.5671.

Rahmatia, R., Pajarianto, H., Kadir, A., Ulpi, W., \& Yusuf, M. (2021). Pengembangan Model Bermain Konstruktif dengan Media Balok untuk Meningkatkan Visual-Spasial Anak. Jurnal Obsesi: Jurnal Pendidikan Anak Usia Dini, 6(1). https://doi.org/10.31004/obsesi.v6i1.1185.

Rozhana, K. M., \& Harnanik, H. (2019). Lesson Study dengan Metode Discovery Learning dan Problem Based Instruction. Intelegensi: Jurnal Ilmu Pendidikan, 1(2). https://doi.org/10.33366/ilg.v1i2.1355.

Sofyan. (2016). Pembelajaran Problem Based Learning dalam Implementasi Kurikulum 2013 di SMK. Jurnal Pendidikan Vokasi, 6(3), 260-271. https://doi.org/10.21831/jpv.v6i3.11275.

Sujana, D. M. A., Dharsana, I. K., \& Jayanta, I. N. L. (2018). Pengaruh Model Pembelajaran Kooperatif Tipe Two Stay Two Stray melalui Lesson Study terhadap Hasil Belajar IPA. MIMBAR PGSD Undiksha, 6(2). http://dx.doi.org/10.23887/jjpgsd.v6i2.19462.

Sutama, I. P. E., Dibia, I. K., \& Margunayasa, I. G. (2017). Pengaruh Model Pembelajaran 
Think Pair Share (TPS) Berbantuan Media Konkret Terhadap Hasil Belajar IPA. MIMBAR PGSD Undiksha, 5. http://dx.doi.org/10.23887/jjpgsd.v5i2.10683.

Syairani, \& Tarigan. (2015). Efektivitas Model Pembelajaran Berbasis Masalah (Problem Based Learning) Terhadap Hasil Belajar Siswa Pada Sub Materi Ekosistem Di Kelas X Sma Negeri 1 Percut Sei Tuan T.P. 2014/2015. Jurnal Pelita Pendidikan, 3(4). https://doi.org/10.24114/jpp.v3i4.4008.

Taqiya, Nuroso, \& Reffiane. (2019). Pengaruh Model Pembelajaran Terpadu Tipe Connected Berbantu Media Video Animasi. Mimbar PGSD Undiksha, 7(3), 289-295. http://dx.doi.org/10.23887/jjpgsd.v7i3.19492.

Triana, Garminah, \& Suartama. (2016). Penerapan Model Pembelajaran Debat Aktif Untuk Meningkatkan Keterampilan Berbicara Siswa Kelas V SD. Jurnal Mimbar PGSD Universitas Pendidikan Ganesha, 4(1). http://dx.doi.org/10.23887/jjpgsd.v4i1.6938.

Wahyuni, Margunayasa, \& Wibawa. (2017). Pengaruh Model problem based learning Berorientasi Tri Hita Karana Terhadap Hasil Belajar Ipa Siswa Kelas V. Jurnal Pendidikan Multikultural Indonesia, 5(2), 1-10. https://doi.org/10.23887/jpmu.v1i2.20771.

Wati, Darsana, \& Suardika. (2014). Pengaruh Model Pembelajaran Somatic, Auditory, Visual, Intelectual (SAVI) Berbantuan Bahan Ajar Terhadap Hasil Belajar IPS Siswa Kelas V SD Gugus Raden Ajeng Kartini. Mimbar PGSD Undiksha, 2(1). http://dx.doi.org/10.23887/jjpgsd.v2i1.3002.

Widnyana, I. G., Sujana, I. W., \& Putra, I. K. A. (2017). Pengaruh Model Pembelajaran Role Playing Berbasis Tri Hita Karana Terhadap Kompetensi Pengetahuan IPS Kecamatan Denpasar Timur Tahun Pelajaran 2016 / 2017. Mimbar PGSD Undiksha, 5(2). http://dx.doi.org/10.23887/jjpgsd.v5i2.11995.

Winursiti. (2017). Penerapan Model Problem Based Learning Berbantuan Reinforcement Simbolik Untuk Meningkatkan Motivasi Dan Hasil Belajar Matematika Siswa Kelas IVB di SD Lab Undiksha. Jurnal Ilmiah Sekolah Dasar, 17(2), 270-275. http://dx.doi.org/10.23887/jisd.v1i4.12120.

Wulandari, A., \& Suparno, S. (2020). Pengaruh Model Problem Based Learning terhadap Kemampuan Karakter Kerjasama Anak Usia Dini. Jurnal Obsesi : Jurnal Pendidikan Anak Usia Dini, 4(2). https://doi.org/10.31004/obsesi.v4i2.448.

Yazar Soyad1, B. B. (2015). Creative and Critical Thinking Skills in Problem-based Learning Environments. Journal of Gifted Education and Creativity, 2(2), 71-71. https://doi.org/10.18200/jgedc.2015214253. 